Health, the perfect ease with which a diploma can be obtained from many of the medical schools of the country, and who, at the same time, stand at the head of the accredited organ of the American Medical Association, can illy afford--so it would seem to me-to make use of the veritable arguments of the " Sweet Family," "natural bone-setters," and others of like ilk.

Will you kindly inform me why, when our Govern. ment in the early days of $186 \mathrm{I}$ found a great necessity existing for reliable medical men, it established through Congressional enactment a special corps of surgeons and assistant-surgeons under the name and title of Surgeons and Assistant-Surgeons U. S. Vols. General Staff, and designated their duties as being confined to such positions as Medical Directors of Army Corps, Division and Brigade Surgeons, Surgeons in charge of General Hospitals, and Medical Inspectors of Armies and Departments? And also, why all applicants for these positions were obliged to submit to a rigid examination before an Army Board appointed for that special purpose? And also, why, as a further criterion, no person successfully passing said examination should receive the appointment of Surgeon unless he was at least 30 years of age?

Has not Dr. Gihon set forth in most striking terms the utter absurdity of many of the examinations made before the Army Medical Boards of to-day, and shown the shameful ignorance manifested by many of the applicants for positions?

The facts are as $I$ have stated. In our country, under the existing form of government, there can never be any limit placed by law upon the number of medical schools that shall graduate students. Neither can there be any uniform standard of requirements for such graduation enforced. We must face these facts; no logic, no reasoning, no anything will change them. The consequence is that our entire country is flooded with graduated doctors, good, bad and indifferent, but in swarms and multitudes. I am not taking into account the armies of quacks and irregulars, only those supposed to be regulars.

How is it possible for the people to select from these masses with judgment? It is in this extremity that I ask relief in the establishment of higher grades in the profession-not in the spirit of aggression, but in the spirit of progress.

As in our civil war the surgeons and assistantsurgeons, U. S. Vols. Gen. Staff, were on a par with the medical officers of the regular army, by reason of the increased demands in the way of examinations, etc., made upon them by the government, and which were not made upon the great bulk of surgeons and assistant-surgeons appointed from the different states; and as a commission in this special corps placed its possessor at once and without hesitation, on a certain established basis, so I would have in the great professional field higher organizations, entrance to which can only be had except by the attainment to certain standards, then a diploma, or certificate, or whatever might be used to signify that the possessor had complied with the requirements, the fact of such possession would give him recognition at once.
I would not have you or any one else infer that I for one moment could or would convey the impression that there were not just as eminent medical men, just as able surgeons on duty with the regiments from the different states during the war as could be found in the regular Army Corps or that of the U. S. Vols. Gen. Staff. Nor would I dare to say that in the rank and file of the profession there might not remain men infinitely superior to those entering the higher grades. What I do mean to say, is that the possession of a higher title would give a man recognition at once wherever he might be, or wherever he might go. Neither the laity or the profession could make any very serious mistakes in demanding his services, either for advice or consultation. At the same time it would be a direct stimulant to a higher education, and those schools that did not bring their matriculants up to the required standard on final examinations, would find themselves dropping out of the race for want of material.

I send you this as a letter, and ask you to publish it as correspondence. You may criticize as severely as you will, only give me opportunity for reply.

$$
\text { Very truly yours, }
$$

A. M. WILDER, M.D.,

Late Surgeon and Brevt. Lieut.-Col. U. S. Vols. Prof. Ophthalmology and Otology Med. Dept. University of California.

\section{PHILADELPHIA LETTER.}

Philadelphia, OCt. $3 \mathrm{x}, \mathrm{I} 884$.

Dear Doctor:-Our schools are fairly at work, and it would seem as though with the array of talent offered in our city that we ought to educate medically to a certain extent. What we do turn out, may seem good enough for the outside world, but it would seem as though for home use it were of no value. We are led to this view by the recent selections by two of our schools. The Jefferson has always preferred to import her professors, and perhaps she knew so well the calibre of her graduates that she had reason to look elsewhere. But now comes the University whose trustees are compelled to look to a foreign land for the occupant of a chair. As if to confirm the view as above, our almshouse has been compelled to import its head nurse from England. We have had for many years her Nurse Training Schools actively at work, but neither seems capable of producing results fit to carry on the work required in the great hospital connected with the almshouse.

The old plan is reversed. In place of going abroad to study, we import teachers, and perhaps at some distant day we may educate men and women fit to take their places.

Our city is dirty, but healthy. Dirt alone does not seem to produce disease. Thanks to the wretched paving, it is difficult to clean the streets, and thanks equally to official inefficiency they are not cleaned. Our daily papers almost constantly growl over this state of things, but it is of no consequence. Should the cholera approach, we may expect a spasmodic effort when too late. But after all, it reminds one of a paper on Cholera Infantum read some years ago before 
our local medical society in which the author announced that the disease was the result of filth and heat. When he had concluded, a member asked, if that were true, how was it possible that any of the children in a certain locality escaped, inasmuch as said neighborhood was remarkable for its filth, and yet during the summer just passed, cholera infantum, in fact all forms of disease had failed to occur, and the whole region was as remarkable for its health.

Speaking of medical societies brings up the fact that cur County Medical Society now numbers its members up to about 500. This is the union of all specialists and general practitioners; while the Pathological, the Obstetrical, the Neurological, the MedicoLegal, etc., devote their evenings to the subjects after which they are named. Judging by the volumes put forth, each body seems to succeed in evolving from its members a goodly share of work.

Our clinics under the name of dispensaries and hospitals are numerous, and show that not only the younger members of the profession but miny of the older ones devote a goodly portion of their time to free prescribing. We had nearly said "for the poor," but this would have been a great error. Fully half of those who apply at such places are abundantly able to pay for both medicine and advice. We have just been told of a case now receiving first-class advice at a public clinic, yet the patient is the daughter of a man owning four horses, several houses, and who is doing an excellent business. Knowing these things, is it any wonder that our profession is crowded here? or that the members must resort to a variety of plans to keep the wolf from the door? Yours,

Philadelphia.

\section{OVARIOTOMY}

\section{To THE EDITOR:}

Dear Sir.-In your issue of October 25, you publish a letter from Prof. Donald McLean, of Detroit. In this he corrects his statement of statistics, made in Washington last May. At that meeting he said that from Oct. I, I 883 , to May, I884, he had done five ovariotomies, and that all the cases had recovered. He now says that one of these cases died. That leaves him then with five ovariotomies from Oct. I, $\mathbf{8 8 3}$, to May, 1884, with one death and four recoveries. Now, I have in my possession a copy of the death certificate of another. She died on the zoth day of January, I 884, at Lanșing, Mich. Will Prof. McLean recall this case also?

$$
\text { Very respectfully yours, }
$$

R. S. Sutton.

4I 9 Pennsylvania Avenue, Pittsburgh, Pa.

\section{BOOK REVIEWS.}

On Tumors of the Bladder, their Nature, Symptoms and Surgical Treatment, Preceded by a Consideration of the best Methods of Diagnosing all forms of Vesical Disease, including Digital Explopation and its Results, by SIR HENRY Thompson,
F.R.C.S., M.B., etc. Phila.: Blakiston, Son \& Co. I 884 Pp. r 10 (with six plates).

We believe this monograph is the first important contribution to the new and important question of digital exploration of the bladder.

Although the work is entitled "Tumors of the Bladder," yet the vital part of it is contained in the discussion of cystotomy as a justifiable resource in obscure cases of bladder disease, as a step toward diagnosis by digital exploration of the interior of that organ.

This is true first, because no case of tumor can be diagnosed or treated without cystotomy as a preliminary step, and, secondly, because the operation, which is not a serious one, gives marked relief in a large number of cases, even where no tumor is found which can be removed. The relief thus seen to follow, is due to the perfect rest from distension, tenesmus and catheterization which the perincal upening allows to the inflamed organ.

Primarily, therefore, tims little book sets out to approve and justify the opening of the bladder for exploration in a large number of cases which heretofore have baffled surgical skill. As this is a question which has for some years been pretty frequently in the minds of surgeons on theorctical grounds, the present contribution will be regarded as settling a vexed question, so far as one man's authority can decide.

In speaking of a tumor found at the autopsy on a case of fatal bladder disease, Sir Henry says :

"It was clear to me from this case that the ordinary sound, "a lengthened finger" in practised hands, had proved incapalle of giving me sufficient information relative to the presence of a considerable growth within the bladder. Supposing that I could but once have put my real finger there, instantly discovering, as I should have done, that easily removable tumor, how different would have been the issue of that unhappy case! He might have been enjoying life and health to-day. What, then, was to prevent me in future, under circumstances of equal gravity and like obscurity, from determining the presence or absence of such a growth by the direct sense of touch, as I could easily have done had the necessity for applying it ever occurred to me? The questions, therefore, naturally presented were: Might it not be possible to examine with my finger the whole interior surface of the bladder; and, if so, from what region could such exploration be most easily and safely accomplished-from the perinxum or from the pubes?"-Pp. IO-II.

Here we find stated at once the rationale and the justification of the operation for digital exploration of the bladder.

Histories in detail are given of forty-three cases where it was performed. In twenty of these tumors of the interior of the bladder were actually found present and removed. In most of the remainder marked relief followed the operation. Six admirable colored plates and a number of engravings add to the clearness of the work.

E. W. A.

An Aid to Materia Medica. Robert H. M. DawBaIN, M.D., New York. J. H. Vail \& Co. Cloth, $86 \mathrm{pp}$.

Contains Drugs, Officinal Preparations, their strength, dosage, etc. Table of the solubility of chemicals in water and alcohol. Simple methods of metric prescription writing. The author's rule for 